\title{
Interaction of smoking, uptake of polycyclic aromatic hydrocarbons, and cytochrome P450IA2 activity among foundry workers
}

\author{
D Sherson, T Sigsgaard, E Overgaard S Loft, H E Poulsen, F J Jongeneelen
}

\begin{abstract}
An increased lung cancer risk has been described among foundry workers. Polycyclic aromatic hydrocarbons (PAHs) and silica are possible aetiological factors. This study describes a urinary PAH metabolite, 1hydroxypyrene (hpU), as well as the degree of cytochrome P450IA2 activity/induction as reflected by the urinary caffeine ratio (IA2) in 45 foundry workers and 52 controls; IA2 was defined as the ratio of paraxanthine 7-demethylation products to a paraxanthine 8-hydroxylation product (1,7-dimethyluric acid). Mean exposure concentrations for foundry workers were defined by breathing zone hygienic samples (respirable dust 1.2 to $3.52 \mathrm{mg} / \mathrm{m}^{3}$ (93 samples)) and as total PAH $\left(0.46 \mu \mathrm{g} / \mathrm{m}^{3}\right)$ and pyrene concentrations $\left(0.28 \mu \mathrm{g} / \mathrm{m}^{3}\right)$ (six samples). Non-smoking controls and foundry workers had similar IA2 ratios $(5.63,95 \%$ confidence interval ( $95 \% \mathrm{CI}) 4 \cdot 56-6 \cdot 70$ and $4 \cdot 40$, 95\% CI 3.56-5.24). The same was true for smoking controls and foundry workers $(9 \cdot 10$, 95\% CI 8.00-10.20 and 8.69, 95\% CI 7.37-10.01). Both smoking groups had raised $\mathrm{IA2}$ ratios compared with non-smokers $(p<0.01)$. Nonsmoking controls and foundry workers had similar hpU concentrations $(0 \cdot 16,95 \%$ CI $0 \cdot 10-$
\end{abstract}

Department of Occupational Medicine, Vejle County Hospital, 7100 Vijle, Denmark

D Sherson, E Overgaard

Institute of Environmental and Occupational Medicine, University of Aarhus, Universitetsparken, 8000 Aarhus, Denmark

T Sigsgaard

Institute of Pharmacology, University of Copenhagen, Juliane Moriesvej 20, 2000 Copenhagen, Denmark

S Loft, H E Poulsen

Department of Toxicology, University of Nijmegen, PO Box 9101, 6500 HB Nijmegen, Holland

F J Jongeneelen
0.22 and $0.11,95 \%$ CI $0.09-0.13 \mu \mathrm{mol} / \mathrm{mol}$ creatinine). Smoking foundry workers had raised hpU concentrations $(0 \cdot 42,95 \%$ CI $0 \cdot 25-$ $0.59)$ compared with smoking controls $(0 \cdot 26$, $95 \%$ CI $0.18-0.34)(p<0.01)$. A small subgroup of smoking foundry workers with the highest exposures to both silica and PAH also had the highest hpU concentrations $(0 \cdot 70,95 \%$ CI - 0.07-1.47 $\mu \mathrm{mol} / \mathrm{mol}$ creatinine) $(p<0.04)$. Increased hpU concentrations in smoking foundry workers suggest a more than additive effect from smoking and foundry exposures resulting in increased PAH uptake. Increased P450IA2 enzyme activity was only found in smokers and no additional effect of foundry exposures was seen. These data suggest that smoking as well as work related PAH exposure may be causally related to increased risk of lung cancer in foundry workers.

Many studies have shown an increased risk of lung cancer among iron foundry workers (for example ${ }^{1-3}$ ). A working group of the International Agency for Research on Cancer described iron founding as a cause of lung cancer in humans. ${ }^{4}$ Polycyclic aromatic hydrocarbons (PAHs) from heated moulds may be an aetiological factor.

A urinary metabolite of pyrene, 1-hydroxypyrene (hpU), has been used to monitor exposure to PAH in road paving and coke oven workers as well as in psoriatic patients treated with coal tar. ${ }^{5-7}$ The cytochrome P450IA subfamily is inducible by PAHs as well as responsible for their metabolic activation to ultimate carcinogens. ${ }^{8}$ Moreover, the content and activity of cytochrome P4501A2 is increased in smokers, an effect thought to be related to PAHs in the smoke. ${ }^{9}$ This activity can be assessed by measuring the metabolic ratios of dietary caffeine. ${ }^{10-12}$ The purpose of the present investigation was to compare urinary excretion of hpU and cytochrome P450IA2 activity in foundry workers occupationally exposed to PAHs with unexposed controls. 
Table 1 Characteristics of the study populations (mean values $(S D)$ )

\begin{tabular}{|c|c|c|}
\hline & $\begin{array}{l}\text { Control group } \\
\text { (water purification } \\
\text { workers; } n=52 \text { ) }\end{array}$ & $\begin{array}{l}\text { Exposed group } \\
\text { (foundry workers; } \\
n=45 \text { ) }\end{array}$ \\
\hline \multirow{4}{*}{$\begin{array}{l}\text { Age (y) } \\
\text { Pack-years } \\
\text { Daily cigarette } \\
\text { equivalents } \\
\text { Urinary creatinine } \\
\text { (mmol/l) }\end{array}$} & \multicolumn{2}{|c|}{ Smokers } \\
\hline & $\begin{array}{l}45 \cdot 6(10 \cdot 7) \\
23 \cdot 2(15 \cdot 8)\end{array}$ & $\begin{array}{l}45.8(11.8) \\
25.7(14.5)\end{array}$ \\
\hline & $18 \cdot 3(7 \cdot 6)$ & $19 \cdot 5(6 \cdot 2)$ \\
\hline & (2) & $10.1(5,0)$ \\
\hline \multirow{3}{*}{$\begin{array}{l}\text { Age }(y) \\
\text { Urinary creatinine } \\
(\mathrm{mmol} / \mathrm{l})\end{array}$} & \multicolumn{2}{|c|}{ Non-smokers } \\
\hline & $41 \cdot 6(12 \cdot 2)$ & $39 \cdot 1(13.9)$ \\
\hline & $11 \cdot 5(7 \cdot 4)$ & $14.5(5.3)$ \\
\hline
\end{tabular}

\section{Subjects and methods}

STUDY POPULATION AND CONTROL GROUP

The study population consisted of $\mathbf{4 5}$ workers from an iron foundry located in rural Denmark (10 women and 35 men). Benzo(a)pyrene serum protein adduct concentrations have previously been described in this population. ${ }^{13}$ The control group consisted of 52 male workers from several water purification plants. Controls were not occupationally exposed to PAHs. These groups were matched for age and smoking habits (table 1).

Information concerning employment, smoking, alcohol consumption, respiratory symptoms, medications, and use of coal tar salves was collected from self completed questionnaires and personal interviews. Pipe tobacco, cigars (5 g tobacco per cigar), and cheroots ( $3 \mathrm{~g}$ tobacco per cheroot) were translated to cigarette equivalents ( $1 \mathrm{~g}$ tobacco per cigarette) when calculating pack-years. The research protocol was approved by the local ethics committee.

\section{EXPOSURE GROUPS AND AIR SAMPLING}

Foundry workers were subdivided into high and low exposure groups for PAHs and silica based on breathing zone measurements (PAHs $\mathrm{n}=9$ and silica $\mathbf{n}=93) \cdot{ }^{13}$ Both gaseous and dust adsorbed PAHs were determined in six hour samples. The PAHs were removed from filters and tubes using acetonitrile and analysed by high pressure liquid chromatography (HPLC). The individual PAHs were identified by ultraviolet and fluorescence techniques. The detection limit for pyrene was $0 \cdot 1 \mu \mathrm{g} / \mathrm{m}^{3}$. These analyses were performed by the Danish National Institute of Occupational Health, Copenhagen.

The high PAH exposure group (casting, hand moulding, shakeout, and oven workers) was exposed to mean values of $6.41 \mu \mathrm{g} / \mathrm{m}^{3}$ total PAHs and $0.28 \mu \mathrm{g} /$ $\mathrm{m}^{3}$ pyrene. The low PAH group (core making, machine moulding, cleaning, and administrators) was exposed to $0.46 \mu \mathrm{g} / \mathrm{m}^{3}$ total PAHs, whereas pyrene was undetectable. The high silica exposure group (hand moulding, casting, shakeout, and cleaning) had mean exposures between 1.50 and $3.52 \mathrm{mg} /$ $\mathrm{m}^{3}$ respirable dust. Mean quartz content was between 4 and $9 \%$. The low silica group (core making, machine moulding, oven workers, and administrators) had mean exposures of less than $0.61 \%$.

\section{URINE COLLECTION AND DETERMINATION OF}

1-HYDROXYPYRENE AND CREATININE

Urine samples $(50 \mathrm{ml})$ were collected from exposed subjects at least five weeks after the summer vacation on two Friday mornings in September 1988 at the foundry. Specimens were stored at $-20^{\circ} \mathrm{C}$. Urinary metabolites were deconjugated by enzymatic hydrolysis and a solid phase sample clean up was applied. The sum of free and conjugated 1hydroxypyrene was determined by HPLC analysis and corrected for creatinine. A full description of the method is presented elsewhere. ${ }^{14}$ The kinetic Jaffé method with a slight variation (final phosphate concentration of 6.6 instead of $4.8 \mathrm{mmol} / \mathrm{l}$ ) was used to measure creatinine. ${ }^{15}$

URINARY CAFFEINE METABOLITE DETERMINATIONS Caffeine is sequentially metabolised by cytochrome P450IA2, N-acetyl transferase (NAT), or xanthine oxidase (XO). ${ }^{1012}$ The activity of these three enzymes can be estimated from the ratios of the metabolites of dietary caffeine-for example, the content of a cup of coffee-excreted into the urine. The ratio 1-methylxanthine (1X) plus 1-methyl uric acid (1U) plus acetylformylamino uric acid (AFMU): 1,7-dimethyl uric acid $(17 \mathrm{U})$ reflects the P450IA2 activity. ${ }^{12}{ }^{12}$ The ratio AFMU: $1 \mathrm{X}$ indicates acetylator state, and the ratio $1 \mathrm{U}: 1 \mathrm{X}$ is a measure of the activity of xanthine oxidase. ${ }^{10}{ }^{16}$ An AFMU: $1 \mathrm{X}$ ratio of 0.5 or less defined slow acetylators.

The five relevant metabolites of caffeine, AFMU, $1 \mathrm{X}, 1 \mathrm{U}, 1,7$-dimethylxanthine (17X), and $17 \mathrm{U}$ were assayed in duplicate in the urine samples by HPLC as described by Campbell et al. ${ }^{11}$ Standards were prepared in urine collected from a subject after three days on a xanthine free diet. Pure compounds were used as references: $1 \mathrm{X}, 1 \mathrm{U}$, and $17 \mathrm{X}$ were purchased from Sigma (Milwaukee, WI) and 17U from Fluka (Buchs, Switzerland); AFMU was kindly provided by Dr B K Tang, Toronto.

Samples of urine were acidified with $\mathrm{HCl}$ to $\mathrm{pH} 3 \cdot 5$. After addition of $120 \mathrm{mg}$ ammonium sulphate, $200 \mu \mathrm{l}$ of urine was extracted with $6 \mathrm{ml}$ chloroform isopropanol mixture $(90: 10 \mathrm{v} / \mathrm{v})$. The organic phase was dried at $40^{\circ} \mathrm{C}$ under $\mathrm{N}_{2}$. The residue was reconstituted in the eluent $(0.05 \%$ acetic acid methanol mixture $(90: 10 \mathrm{v} / \mathrm{v}))$. The analytical column, a Beckman Ultraphere ODS $(5 \mu \mathrm{m}, 25 \mathrm{~cm})$, was eluted at $1 \mathrm{ml} / \mathrm{min}$. The effluent was monitored at $280 \mathrm{~nm}$. During preparation and extraction and after reconstitution all samples were kept below $5^{\circ} \mathrm{C}$ to conserve 
Table 2 Mean urinary caffeine metabolite (IA2) and xanthine oxidase ( $X O$ ) ratios as well as corrected l-hydroxypyrene ( $h p U, \mu \mathrm{mol} / \mathrm{mol}$ creatinine) and acetylator state (No slow/No fast) with $95 \%$ CIs for controls and foundry workers

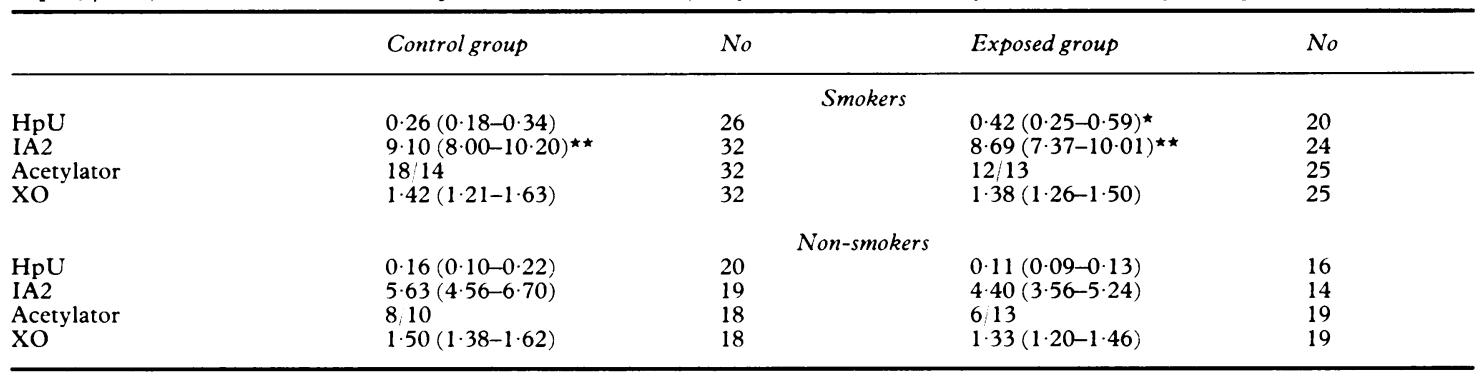

$\star \mathrm{p}=0.01 ; \mathrm{HpU}$ for smokers: controls $v$ exposed groups.

$\star \star \mathrm{p}<0.01$; IA2 for smoking groups compared with their non-smoking counterpart.

AFMU. As the metabolic ratios were derived from the same chromatographic run, no internal standard was used. The analytical interday coefficient of variation of the metabolic ratios was less than $5 \%$. In six urine samples the concentrations of caffeine metabolites were too low to determine the metabolic ratios.

\section{STATISTICAL ANALYSIS}

Data were analysed using the statistical package for social sciences (SPSS). ${ }^{1 i}$ The following statistical methods were employed: Student's $t$ test, nonparametric tests, linear and multiple regression analysis, and ANOVA variation analysis. All tests were two tailed. The number of samples in each analysis could vary due to missing data.

\section{Results}

Table 2 shows the mean urinary caffeine metabolite ratios (IA2) and 1-hydroxypyrene concentrations. The IA2 ratios were almost identical for foundry workers and controls. Smoking controls and foundry workers had significantly raised IA 2 ratios compared with their non-smoking counterparts. No difference in hpU concentrations was found between nonsmoking controls and foundry workers. Smoking foundry workers had significantly higher hpU concentrations compared with smoking controls. Similar acetylator and $\mathrm{XO}$ ratios were seen in all groups.

Figure 1 shows the mean hpU concentrations according to exposure to silica. All smoking groups had significantly raised mean values compared with their non-smoking counterpart. Smoking foundry workers in both low $(0.36,95 \%$ confidence interval $(95 \% \mathrm{CI}) 0 \cdot 26-0 \cdot 46)$ and high $(0 \cdot 47,95 \% \mathrm{CI} 0 \cdot 16-$ 0.78 ) silica exposure groups had significantly higher concentrations than smoking controls $(0 \cdot 26,95 \% \mathrm{CI}$ $0 \cdot 18-0 \cdot 34)$. Non-smoking controls $(0 \cdot 16,95 \%$ CI $0.08-0.24)$ had non-significantly higher hpU concentrations than non-smoking foundry workers with either low $(0.13,95 \%$ CI $0.08-0.18)$ or high $(0.08$, $95 \%$ CI $0 \cdot 03-0 \cdot 13)$ exposure to silica.
Figure 2 shows mean hpU values according to exposure to $\mathrm{PAH}$. All smoking groups had significantly raised mean concentrations compared with their non-smoking counterpart. Smoking foundry workers in the high PAH exposure group $(0.58,95 \% \mathrm{CI}$ $0 \cdot 15-1.01)$ had significantly higher concentrations than smoking controls $(0 \cdot 26,95 \% \mathrm{CI} 0 \cdot 18-0 \cdot 34)$ and non-significantly higher concentrations than lesser exposed foundrymen $(0 \cdot 31,95 \%$ CI $0 \cdot 23-0 \cdot 39)$. Non-smoking controls $(0 \cdot 16,95 \% \mathrm{CI} 0 \cdot 08-0 \cdot 24)$ had non-significantly higher hpU concentrations than non-smoking foundry workers with low $(0 \cdot 11,95 \%$ CI $0.07-0 \cdot 15)$ or high $(0.11,95 \%$ CI $0.06-0 \cdot 16)$ exposure to PAH.

A small subgroup of smoking foundry workers $(0 \cdot 70,95 \%$ CI $-0 \cdot 07-1 \cdot 47)$ with simultaneous high exposure to both silica and PAHs had significantly raised hpU concentrations compared with controls $(0 \cdot 26,95 \% \mathrm{CI} 0 \cdot 19-0 \cdot 33)$ and other foundry workers with mixed exposures $(0 \cdot 32,95 \%$ CI $0.24-0 \cdot 40)$ (see fig 3).

Linear regression analyses failed to show any

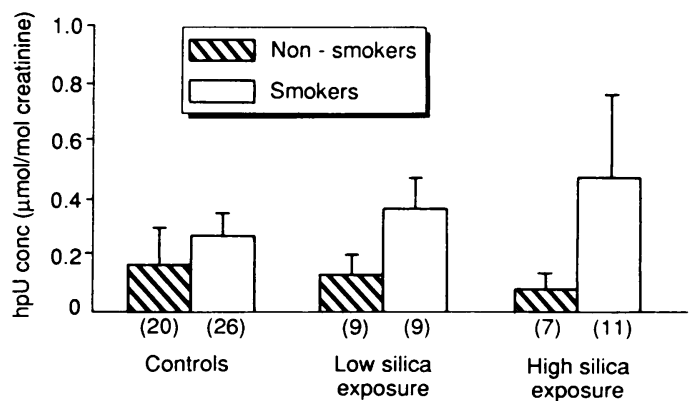

Figure 1 Mean corrected 1-hydroxypyrene ( $h p U$, umol mol creatinine, concentrations with 95". CIs for controls and foundry workers according to silica exposure. The number of samples is given in parentheses. $p<0.05$; smoking controls $v$ smoking foundry workers with either high or low silica exposure. $p<0.01$; all smoking groups compared with their non-smoking counterpart. 


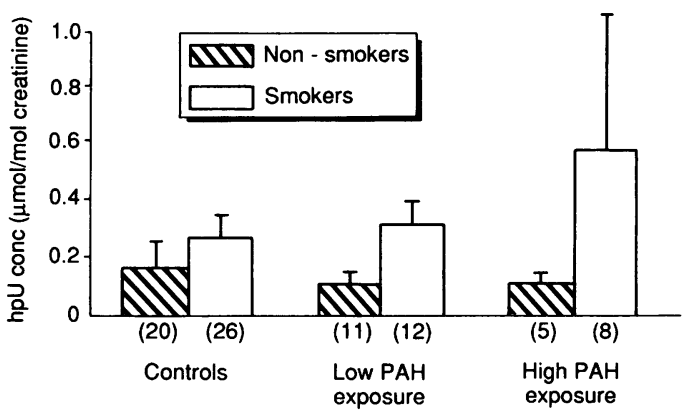

Figure 2 Mean corrected 1-hydroxypyrene ( $h p U$ ) concentrations with $95 \%$ CIs for controls and foundry workers according to $P A H$ exposure. The number of samples is given in parentheses. $p=0.03$; smoking control $v$ smoking foundry workers with high $P A H$ exposure. $p<0.01$; all smoking groups compared to their non-smoking counterpart.

correlation between benzo(a)pyrene serum protein adducts and either IA2 or hpU concentrations. Neither was there any correlation between IA2 and $\mathrm{hpU}$ concentration. Using ANOVA only PAHs $(\mathrm{p}=$ $0.04)$ and smoking $(\mathrm{p}=0.01)$ correlated with $\mathrm{hpU}$ concentration. A significant two way interaction of smoking and PAH exposure on hpU concentrations $(p=0.03)$ was also found by ANOVA. No effects of age, sex, or silica were seen.

\section{Discussion}

Exposure to silica at the present foundry was well characterised by systematic measurements and corresponds to general contents in Danish foundries. ${ }^{18}$ The mean quartz content of between 4 and $9 \%$ was somewhat lower than that in the United States $(11 \%),{ }^{19}$ Canada ( 3 to $\left.25 \%\right),{ }^{20}$ and Finland (7 to $13 \%) .^{21}$

Exposures to PAHs were defined by few measurements. As both gaseous and dust adsorbed

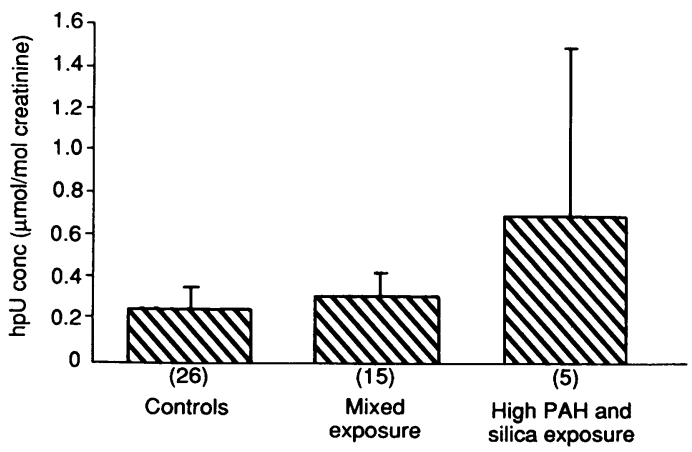

Figure 3 Mean corrected 1-hydroxypyrene ( $h p U$ ) concentrations with $95 \%$ CIs for smoking controls and smoking foundry workers according to exposures. $p<0.01$; controls $v$ either mixed or high exposure groups.
PAHs were determined, the measurements probably give a fairly accurate description of exposure levels. Further sampling of PAHs would have been desirable. In iron foundries in Germany $\left(1.74 \mu \mathrm{g} / \mathrm{m}^{3}\right)^{22}$ and Canada (up to $\left.12.93 \mu \mathrm{g} / \mathrm{m}^{3}\right)^{23}$ much higher air concentrations of pyrene than in the present foundry $\left(0.28 \mu \mathrm{g} / \mathrm{m}^{3}\right)$ have been described. The reason for these differences is uncertain, but may reflect better hygienic conditions or different binding materials. When coal tar derived binders are used, high air concentrations are found. Total exposures to PAHs for roofers $\left(8.32 \mu \mathrm{g} / \mathrm{m}^{3}\right)^{24}$ and chimney sweeps $\left(5.06 \mu \mathrm{g} / \mathrm{m}^{3}\right)^{25}$ are similar to the study foundry. Coke oven workers often have higher exposures. ${ }^{6}$

Which PAH metabolite is most appropriate for biological monitoring of foundry workers is unknown. We chose 1-hydroxypyrene, a metabolite of pyrene, because it has been used for other populations exposed to PAHs. In the present study pyrene was only $4 \%(0 \cdot 28 / 6 \cdot 41)$ of total PAHs. Thus another PAH metabolite associated with a higher exposure might be more appropriate.

In our present study smokers had consistently higher hpU concentrations than non-smokers. Other studies have shown both higher $(0.17-0.62 \mu \mathrm{mol} / \mathrm{mol}$ creatinine $)^{6}$ and similar $(0.26-0.28 \mu \mathrm{mol} / \mathrm{mol}$ creatinine $)^{26} \mathrm{hpU}$ concentrations in smoking controls compared with non-smoking controls. Thus smoking should be controlled for when measuring hpU concentrations.

Only smoking foundry workers had raised hpU concentrations (table 2). These concentrations were similar to those found in workers exposed to petroleum coke dust $(0.54-0.90){ }^{26}$ Higher concentrations have been described, however, in psoriatic patients $(25 \cdot 4-1565 \cdot 0){ }^{7}$ coke oven $(0 \cdot 70-11 \cdot 2){ }^{6}$ creosote wood (up to about 40). ${ }^{27}$ and road paving (about 0.5-8.5) $)^{5}$ workers. These varying concentrations probably reflect different exposures.

Our results suggest a more than additive effect of exposure to PAHs and smoking. Jongeneelen et al reported similar findings among coke oven workers. ${ }^{6}$ Decreased mucociliary clearance and induced enzyme metabolism among smokers may explain this effect. The data presented in figure 3 suggest an additional effect from simultaneous exposure to PAHs and silica. It is interesting to note that a similar effect has been shown for benzo(a)pyrene serum protein adducts in the identical population. ${ }^{13}$ Increased uptake of silica particles with PAHs adsorbed to their surface may explain this phenomenon. ${ }^{28}$

The cytochrome P450IA subfamily is thought to play a major part in the activation of foreign chemicals into toxic compounds. ${ }^{29}$ Of the two enzymes belonging to this family P450IA2 is probably exclusively expressed in the liver whereas P450IA1 is mainly expressed at extrahepatic sites. 
The two enzymes are similar in catalytic specificity and inducibility. The PAHs are preferential substrates, however, and inducers of P450IAl, whereas aromatic amines are preferential substrates and inducers of P450IA2. ${ }^{29}$ In smokers, increased liver microsomal content of P450IA2 as well as in vivo metabolism of its substrate, caffeine, have been shown. ${ }^{911}$ In our present study the metabolic ratio of dietary caffeine reflecting the P450IA2 activity in the liver was almost doubled in smokers compared with non-smokers as shown previously. ${ }^{1130}$ Despite the apparent additive effect of exposure to PAHs and smoking in foundry workers on the excretion of hpU, however, no additive effect regarding the hepatic P450IA2 activity was found. A similar discrepancy between the effect of smoking and occupational exposure to PAHs on the activity of hepatic cytochrome P450, as assessed by the pharmacokinetics of theophylline, has been shown in coke oven workers. ${ }^{31}$ Moreover, extensive exposure to sidestream tobacco smoke rich in PAHs also failed to alter theophylline metabolism. ${ }^{32}$ A possible explanation might be that inhaled PAHs from the working environment or sidestream smoke is metabolised in the lung and never reaches the liver. Some of the enzyme inducing constituents of mainstream tobacco smoke, however, may either be poor substrates for cytochrome P450 in the lung or reach the liver through portal blood after condensation and swallowing. Also, it has been suggested that the inducing effect of smoking is not related to PAHs but to other smoke ingredients such as carbolines and even higher chlorinated dioxins ${ }^{33} \mathrm{~A}$ possible inducing effect of PAHs on cytochrome P450IA1 in the lung could not be assessed with the current methods. Such an effect may explain the apparent additive effect of smoking and exposure to PAHs on the excretion of hpU through increased formation.

In all subgroups (table 2) the distribution of slow and fast acetylators was similar and compatible with that of the Danish population. ${ }^{30}$ Neither foundry work or smoking had any effect on the activity of xanthine oxidase, which may be implicated in oxidative tissue injury related to ischaemia and infection. ${ }^{34} 35$

Several potential confounding factors should be taken into consideration with regard to the present investigation. Dietary factors were not controlled for, but there is no reason to believe that they had any effect. If the minimal concentrations of PAHs that can be found in food and drinking water had a measurable effect, it should be similar in both exposed and control groups. Three foundry workers were under treatment with coal tar salve when samples were collected. This minor treatment had no apparent effect as these workers had low hpU concentrations $(0.12,0.30$, and $0.13 \mu \mathrm{mol} / \mathrm{mol}$ creatinine $)$. No alcohol abuse was found in either exposed or control subjects. Thus alcohol ingestion was unlikely to have influenced the results. Tests of liver function were not performed. Women were included in the exposed group but not in the controls. As 1-hydroxypyrene was corrected using creatinine, any potential effect of differing muscle mass between men and women should have been eliminated but potential differences in uptake and metabolism were not evaluated. The metabolic ratios of caffeine are not influenced by sex. ${ }^{11}{ }^{30}$ Multiple regression analysis showed no effect of either sex or age.

In conclusion our data have shown raised concentrations of pyrene urinary metabolite (hpU) in smoking foundry workers. An additive effect from smoking and foundry exosure is suggested. Increased P450IA2 activity was only seen in smokers with no additional effect of foundry work. These data suggest that smoking as well as work related exposure to PAHs may be causally related to increased risk of lung cancer in foundry workers.

We appreciate the financial support provided by the Vejle County Medical Research Fund and the Danish Medical Research Council. Åse Marie Hansen, Danish National Institute of Occupational Health, has kindly performed PAH determinations on air samples. The Department of Clinical Chemistry carried out the creatinine determinations.

Requests for reprints to: David Sherson, Department of Occupational Medicine, Vejle County Hospital, 7100 Vejle, Denmark.

1 Silverstein M, Maizlish N, Park R, Silverstein B, Brodsky L, Mirer F. Mortality among ferrous foundry workers. Am J Ind Med 1986;10:37-43.

2 Fletcher AC, Ades A. Lung cancer mortality in a cohort of English foundry workers. Scand J Work Environ Health 1984;10:7-16.

3 Sherson $D$, Svane $O$, Lynge $E$. Cancer incidence among foundry workers in Denmark. Arch Environ Health 1991;46:75-81.

4 International Agency for Research on Cancer. Overall evaluations of carcinogenicity: an updating of IARC monographs 142. Lyon: IARC, 1987. (IARC monographs on the evaluation of carcinogenic risks for humans; suppl 7).

5 Jongeneelen FJ, Scheepers PTJ, Groenendijk A, et al. Airborne concentrations, skin contamination, and urinary metabolite excretion of polycyclic aomatic hydrocarbons among paving workers exposed to coal tar derived road tars. Am Ind Assoc J 1988;12:600-7.

6 Jongeneelen FJ, van Leeuwen FE, Oosterink S, et al. Ambient and biological monitoring of cokeoven workers; determinants of the internal dose of polycyclic aromatic hydrocarbons. $\mathrm{Br} \mathrm{J}$ Ind Med 1990;47:454-61.

7 Clonfero E, Zordan M, Venier P, et al. Biological monitoring of human exposure to coal tar: urinary excretion of total polycyclic aromatic hydrocarbons, 1-hydroxypyrene and mutagens in psoriatic patients. Int Arch Occup Environ Health 1989;61:363-8.

8 Guengerich FP. Roles of cytochrome P-450 enzymes in chemical carcinogenesis and cancer chemotherapy. Perspect Cancer Res 1988;48:2946-54.

9 Sesardic D, Boobis AR, Edwards RJ, Davies DS. A form of cytochrome P450 in man, ortologous to form $d$ in the rat, catalyses the $\mathrm{O}$-deethylation of phenacetin and is inducible by cigarette smoking. Br J Clin Pharmacol 1988;26:363-72.

10 Grant DM, Tang BK, Kalow W. Variability in caffeine metabolism. Clin Pharmacol Ther 1983;33:591-602. 
11 Campbell ME, Spielberg SP, Kalow W. A urinary metabolite ratio that reflects systemic caffeine clearance. Clin Pharmacol Ther 1987;42:157-65.

12 Butler MA, Iwasaki M, Guengerich FP, Kadlubar FF. Human cytochrome P-450 $\mathrm{PA}_{\mathrm{A}}$ (P-450IA2), the phenacetin O-deethylase, is primarily responsible for the hepatic 3-demethylation of caffeine and $\mathrm{N}$-oxidation of carcinogenic arylamines. Proc Natl Acad Sci USA 1989;86:7696-700.

13 Sherson D, Sabro P, Sigsgaard T, Johansen F, Autrup H. Biological monitoring of foundry workers exposed to polycyclic aromatic hydrocarbons. Br J Ind Med 1990;47:448-53.

14 Jongeneelen FJ, Anzion RBM, Henderson PT. Determination of hydroxylated metabolites of polycyclic aromatic hydrocarbons in urine. J Chromatogr 1987;413:227-32.

15 Bergman A, Öhaman G. Effect of detergent on kinetic Jaffémethod assay of creatinine. Clin Chem 1980;26:1729-32.

16 Grant DM, Tang BK, Campbell ME, Kalow W. Effect of allopurinol on caffeine disposition in man. Br J Clin Pharmacol 1986;21:454-8.

17 Noruses MJ, ed. Statistical package for social sciences (SPSS) $P C+V 2.0$ ). Base manual for the IBM PC/XT/AT and PS $/ 2$. Chicago: SPSS Inc., 1988.

18 Sherson D, Breum NO. Silicosis: a review. In: Peters GA, Peters BJ, eds. Source book on asbestos diseases, vol 5. London: Butterworth and $\mathrm{Co}$. (in press).

19 Oudiz J, Brown JW, Ayer HE, Samuels S. A report on silica exposure levels in United States foundries. Am Ind Hyg Assoc $J 1983 ; 44: 374-6$.

20 Ayalp A, Myroniuk D. Evaluation of occupational exposure to free silica in Alberta foundries. Am Ind Hyg Assoc J 1982; 43:825-31.

21 Siltanen E, Koponen M, Kokko A, Ingstom B, Reponen J. Dust exposure in Finnish foundries. Scand $J$ Work Environ Health 1976;2(suppl 1):19-31.

22 Knecht U, Elliehausen $\mathrm{HJ}$, Woitowitz $\mathrm{HJ}$. Gaseous and adsorbed PAH in an iron foundry. Br $J$ Ind Med 1986;43: 834-8.

23 Verma DK, Muir CDF, Cunliffe S, Julian JA, Vogt JH, Rosenfeld J. Polycyclic aromatic hydrocarbons in Ontario foundry environments. Ann Occup Hyg 1982;25:17-25.

24 Herbert R, Marcus M, Wolff M, et al. Detection of adducts of deoxyribonucleic acid in white blood cells of roofers by ${ }^{32} \mathrm{P}-$ postlabeling. Scand J Work Environ Health 1990;16:135-43.

25 Knecht U, Bolm-Audorff U, Woitowitz HJ. Atmospheric concentrations of polycyclic aromatic hydrocarbons during chimney sweeping. Br J Ind Med 1989;46:479-82.

26 Jongeneelen FJ, Anzion RBM, Theuws JLG, Bos RP. Urinary 1-hydroxypyrene levels in handling petroleum coke. J Toxicol Environ Health 1989;26:133-6.

27 Jongeneelen FJ, Bos RP, Henderson PT. Metabolites of polycyclic aromatic hydrocarbons in urine of exposed workers. Toxicological and Environmental Chemistry 1988;16:295-307.

28 Lakowicz JR, Bevan DR. Effects of adsorption of benzo(a)pyrene to asbestos and non-fibrous mineral particulates upon its rate of uptake into phospholipid vesicles and rat microsomes. In: Brown RC, Gormley IP, Chamberlain M, Davies R, eds. The in vitro effects of mineral dusts. London: Academic Press, 1980;169-75.

29 Ioannides C, Parke DV. The cytochrome P450 I gene family of microsomal hemoproteins and their role in the metabolic activation of chemicals. Drug Metab Rev 1990;22:1-85.

30 Vistisen K, Loft S, Poulsen HE. Cytochrome P450IA2 activity in man measured by caffeine metabolism: effect of smoking, broccoli and exercise. In: Witmed CM, ed. Biological reactive intermediates IV. New York: Plenum Press 1990:407-11.

31 Haughey DB, Jusco WJ. Theophylline disposition in foundry workers exposed to coke oven effluent. Biopharmaceutics and Drug Disposition 1988;9:405-9.

32 Casto, DT, Schnapf BM, Clotz MA. Lack of effect of short-term passive smoking on the metabolic disposition of theophylline. Eur J Clin Pharmacol 1990;39:399-402.

33 Remmer $\mathbf{H}$. Induction and its influence on human cancer. Pharmacol Ther 1987;33:89-94.

34 Simpson PJ, Lucchesi BR. Free radicals and myocardial ischemia and reperfusion injury. J Lab Clin Med 1987;110: 13-30.

35 Oda T, Akaike T, Hamamoto T, Suzuki F, Hirano T, Maeda H. Oxygen radicals in influenza-induced pathogenesis and treatment with pyran polymer-conjugated SOD. Science 1989; 244:974-6.

Accepted 8 July 1991. 